\title{
PRESIÓN COLONIAL Y REIVINDICACIÓN INDÍGENA EN CAJAMARCA (1785-1820) SEGÚN EL ARCHIVO DEL "Protector DE NATURALES"
}

Bernard Lavallè

DE UNOS QUINCE años a esta 'parte, el recurso cada vez más frecuente a los archivos locales es una de las características dominantes de las nuevas orientaciones de la historiografía peruana sobre la época colonial. Así, se fueron renovando, vivificando y matizando los análisis hasta entonces fundamentados y estructurados esencialmente a partir de repositorios conservados en Lima o Sevilla.

Curiosamente, en tal contexto, Cajamarca que fuera en la época española la cabecera de un corregimiento a la vez amplio, poblado y activo - de hecho la verdadera capital de los Andes del norte a pesar de la decisión colonial de establecer en la costa, en Trujillo, la sede del obispado - no parece haber suscitado las investigaciones que obviamente se merece y son posibles dada la riqueza de su archivo departamental notablemente clasificado $y$ bien conservado.

Entre otros fondos, sus series corregimiento $e$ intendencia conservan, cada una, una sección titulada protector de naturales subdividida en ambos casos en causas ordinarias y causas criminales. En la primera serie 


\section{Bernard Lavalle}

(1605-1784) están reunidos respectivamente 34 y 4 legajos, en la segunda (1785-1820) 5 y 6 legajos.

Dado el carácter original de tal conjunto y su naturaleza desde muchos puntos de vista excepcional, ya que bien pocos son los archivos que conservan tales fondos de manera individualizada y tan completa, nos proponemos analizarlo pero ciñendo nuestro propósito, de momento, al período posterior a la creación de la intendencia, esto es a partir de 1785.

Después de la gran reforma que, bajo la autoridad de Escobedo, había de desembocar en 1784 en la reorganización administrativa y territorial que sabemos, Cajamarca se convirtió en la sede de uno de los ocho partidos de la intendencia de Trujillo que entonces se creó. El antiguo corregimiento de Cajamarca había sido uno de los más vastos del Perú colonial. Según Antonio de Alcedo, se extendia en efecto en sus mayores dimensiones (SE) NO y SO/NE) en más de $200 \mathrm{~km}$. y administraba a más de cuarenta municipios españoles $e$ indígenas. ${ }^{1}$

Deseando encuadrar mejor y vigilar de más cerca esa región que hacia mediados del XVIII conoció un largo periodo de agitación marcado por varias rebeliones indigenas y mestizas, ${ }^{2}$ en 1759, el entonces virrey conde de Superunda decidió separar de ella la provincia de Huamachuco, haciéndola un nuevo corregimiento. Más tarde, en 1787 , y por lo tanto, poco después de la creación de la intendencia, el partido de Cajamarca perdió también

1 Antonio de Alcedo, Diccionario geográfico de las Indias occidentales o América (1786), Madrid, B A E, t. 205-206, 1967, t 205, p. 261.

2 Scarlett O'Phelan, Rebellions and revolts in eighteenth century Peru and Upper Peru, Colonia-Viena, Böhlau Verlag, 1985, en particular pp. 131 y 285. 


\section{Presion colontal en Cajamarca}

su zona norte (Chota, Cutervo, Hualgáyoc, Los Huambos, Santa (ruz) que pasó a constituir en adelante el partido de Chota. Esas comarcas bastante alejadas de su ex cabecera habian visto crecer de repente su importancia económica dado el auge de las minas de Hualgáyoc que suscitaron entonces muchas $-y$ sobradas- esperanzas por lo cual captaron toda la atención de las autoridades coloniales.

En otros términos, la capital provincial ya no reinaba sino sobre la parte sur del actual departamento (esto es, las provincias de Cajamarca, Celendín, San Miguel y Contumazá) menos Cajabamba que dependía de Huamachuco.

Así y todo, el partido o provincia de Cajamarca seguía, sin embargo, siendo uno de los más importantes del Perú, lo cual a posteriori justificaba de alguna manera los sucesivos desmembramientos que le impusiera la lógica y la voluntad de eficacia de la nueva política administrativa. Para dar una idea de su población, disponemos de dos series de cifras que datan del periodo aquí estudiado: las del célebre obispo de Trujillo, Martínez Compañón (1789) $y$, algunos años más tarde (1795), las del cuadro general de la población peruana establecido por las oficinas limeñas. ${ }^{3}$

$$
\text { Españoles Indios mestizos } \begin{gathered}
\text { negros pardos total } \\
\text { (esclavos } y \\
\text { libres) }
\end{gathered}
$$

$\begin{array}{lllllll}1789 & 7342 & 22720 & 15964 & 493 & 4408 & 50927 \\ 1795 & 5653 & 27314 & 13188 & 507 & & 46662\end{array}$

Con todas las aproximaciones que imaginamos, las cifras de 1795 permiten conocer la importancia relativa del partido de Cajamarca en el conjunto peruano. Con

3 Ver respectivamente La obra del obispo Martínez Compañón sobre Trujillo del Perú en el siglo XVII, Madrid, ed. Cultura hispánica, 1978, t. I s.p. y John Fisher.- Gobierno y sociedad en el Perú colonial; el régimen de las intendencias, 1784-1814, Lima, Univ. Cat., 1981, pp. 274-276. 


\section{Bernard Lavalle}

sus 46,662 habitantes, era uno de los más poblados del país. Si exceptuamos por supuesto a Lima, sólo eran más poblados el partido vecino de Huamachuco y el de Jauja en el rico valle del Mantaro (47,785 h.). En lo que se refiere a los indígenas -que aquí nos interesarán de manera más precisa- Cajamarca era con Huamachuco el partido en que eran más numerosos. ${ }^{4}$ Por fin, en lo que tocaba a los elementos poblacionales de origen europeo, también Cajamarca ocupaba un puesto relevante ya que, fuera de los partidos de Cuzco y Arequipa cuyo peso histórico bien conocemos, sólo el de Huánuco, con 6,099 blancos, lo sobrepasaba.

Para concluir, hay que añadir que a nivel regional la ciudad de Cajamarca era, y por mucho, la primera de la intendencia. Cuando la provincia de la cabecera, Trujillo, reunía apenas 12,000 personas, según Martínez Compañón, la ciudad de Cajamarca por sí sola contaba con más de 17,500 almas.

En una economía fundada esencialmente sobre la explotación de la mano de obra indígena, estas indicaciones dicen mucho en cuanto a la importancia de las actividades regionales. Sus haciendas numerosas y a menudo prósperas se aprovechaban tradicionalmente de los intercambios con las plantaciones cañeras de las zonas de Saña y Lambayeque en la costa. De algunos años a esa parte, eran revitalizadas por el auge minero cuyo eje era Hualgáyoc, $e$ incluian a menudo obrajes especializados en prendas de algodón, frazadas, velas de barcos y otras producciones de menor cuantía (pañetes, sayales y jergas). Cajamarca figuraba así en muy buen rango entre las zonas textiles del norte peruano con Huamachuco, Conchucos, Huaylas e incluso, más al sur, Tarma y Cajatambo.

4 Es de notar que, para Huamachuco, Martínez Campañón da cifras muy inferiores a las de 1795. El obispo llegaba escasamente a 17,000 indios de un total que superaba apenas las 38,000 almas... 


\section{Presion colonial en Chuamarca}

El otro protagonista del que hablaremos, el protector de naturales, también merece que lo presentemos. Por supuesto no se trata aquí de hacer una historia detallada de dicha función sobre la cual mucho queda por decir. Recordemos sencillamente que una real cédula de 1557 había nombrado protector al fiscal del Consejo de Indias que, además de sus otras actividades, tenía el encargo especial de velar por la suerte de los indios ("...de cuya protección y amparo, como personas pobres y miserables, se tenga por muy encargado..."). Más tarde, con el fin de acercar el protector a los potenciales demandantes, otra cédula de 1563 había pasado el título y la función a los fiscales de las audiencias americanas. ${ }^{5}$

Por lo que toca al Perú, se debe al virrey $D$. Francisco de Toledo la organización casi definitiva de la justicia indígena a sus diferentes niveles. Retomando la idea de su predecesor, el conde de Nieva, y según el modelo que él mismo había instituído en el Cusco en 1572, lo había completado decidiendo que, para asuntos de primera instancia, todas las ciudades de españoles tendrían en el seno del cabildo a un juez de naturales elegido cada año. ${ }^{6}$

Hacia finales de 1574, imaginando cómo se habían de tramitar los pleitos en que una de las partes por lo menos era indígena, el virrey había previsto que cada corregimiento tuviera su defensor de los indios, un jurista encargado de recibir sus quejas y de velar por que la justicia los oyera según las reglas previstas. Consejero juridico de los indígenas, era en alguna manera su garante, según los casos ante el corregidor o el juez de naturales, o bien entre el corregidor y la audiencia si el caso se elevaba y había apelación.?

5 Ver Constantino Bayle, Los cabildos seculares en la América española. Madrid. ed. Sapientia, 1952, I. parte, cap. XII.

- Ver Ordenanzas de don Francisco de Toledo virrey del Perú, 1569-1581 ed. R. Levillier, Madrid, 1929, pp. 76 y 81.

7 Ibid. p. 257-271. 


\section{Bernard Lavaue}

En el siglo XVII, siguiendo en grandes líneas el cuadro arriba indicado, el sistema había llegado a su punto de equilibrio definitivo. Varias cédulas de 1614 y 1615 habian liberado de las funciones de protector a los fiscales de Lima y Charcas, considerando las muchas e importantes funciones que desempenaban por otra parte. Se habia instituído, por consiguiente, en ambas audiencias un protector general de los naturales nombrado por el virrey. Al nivel regional, los protectores de los naturales serian sus relevos, como herederos directos de los defensores que creara $D$. Francisco de Toledo, pero no por eso hubo uno en cada corregimiento. Eran en total once en la audiencia de Lima (en Ica, Jauja, Huamanga, Huancavelica, Castrovirreyna, Cuzco, Carabaya, Arequipa, Trujillo y Cajamarca), cinco en la de Charcas (en Potosí, Cochabamba, Chucuito, Oruro y La Paz).

Añadiremos, para concluir, que se trataba de puestos muy mal remunerados. Los protectores cobraban, en efecto, de 200 a 600 pesos anuales -lo cual era poco- pagados por las comunidades indígenas o sobre los residuos de las cajas reales. En algunos casos, el cargo era más tenue aún $y$ sobre todo aleatorio en cuanto a ingresos se refería. El protector de Ica, por ejemplo, cobraba anualmente lo que producian dos fanegas de panllevar trabajadas por los indios. En otros casos, para darle más incentivo económico, el cargo dé protector se confundía con el, -mejor pagado-, de alguacil mayor (Jauja) o de tesorero (Carabaya). ${ }^{8}$

Con la reforma de las intendencias, cada protector siguió recibiendo y tramitando quejas o demandas indigenas, aquellas que los propios campesinos le dirigían directamente, o

- Ver Francisco López de Caravantes, Noticia general del Perú (1630), Madrid, B A E, t 292-293 y 295-296, discursos 5 y 6 passim. 


\section{Presión colonial en Cajamarca}

aquellas que elevaban hasta él los procuradores de indios en función dentro de ciertos pueblos de la provincia. Además de esto, podía actuar también motu propio cuando llegan a conocer procederes o comportamientos cuyas consecuencias le parecian de su incumbencia en la medida en que eran lesivos para la población indigena.

Para los años aquí estudiados, el archivo de Cajamarca conserva más de 450 expedientes, meras denuncias aparentemente sin consecuencias, cuyo seguimiento a veces se abandonaba $u$ olvidaba poco después, o gruesos legajos que atestiguaban años, en algunos casos decenios, de procedimientos y trámites. Del total, 181 eran de la incumbencia de la justicia ordinaria y 276 se clasificaban como causas criminales.

En la primera de estas dos series, más de la mitad corresponden a un trabajo de juez de paz. Se trata de riñas entre vecinos, de quejas por daños a los cultivos o por diferencias en los deslindes, de reclamos suscitados por deudas no pagadas, de herencias disputadas $y$ de los litigios más diversos. Valga por ejemplo el de Pedro Quispe, indio de la guaranga de Guzmango, deseoso de que se le concediese de manera definitiva $y$ oficial el privilegio aparentemente controvertido $-y$ por lo visto contestable ya que no ganó su pleito- de representar a uno de los reyes magos que participaban cada año en la procesión que recorría las calles de su pueblo. ${ }^{9}$

9 "El presente año se le hizo forzoso por la república de los naturales de esta dicha ciudad para que salga imitando a los santos reyes en el día seis de enero, con motivo de ser nieto de Gregorio Quispe, difunto, que es el mismo excercicio que se mantuvo todo el tiempo de su vida en que falleció, y para que lleve término aquella antigüedad el corriente año lo ejecutó con ciega obediencia y para que en lo sucesivo tenga lugar la preferencia de dicha mi parte para salir a la adoración el niño Dios verdadero en paseo público a la parroquia matriz de naturales como es práctica y costumbre de tiempo inmemorial, suplico a la justificación de $\mathrm{V}$. se digne librar el correspondiente decreto que solicito por ceder al cumplimiento de la república indiana". 


\section{Bernard LavaLle}

Otros problemas estaban relacionados con asuntos más conformes con aquellos que normalmente trata la justicia. Así incumbía al protector ser el abogado de los indigenas que deseaban divorciarse. ${ }^{10}$ Encontramos algunos expedientes de este tipo llegados hasta Cajamarca gracias a la intervención de curas doctrineros. Los presentan mujeres que se quejan de los tormentos que les imponen un marido alcohólico o violento, que las lleva a trabajar en tierras calientes donde padecen fiebres palúdicas y a veces, inclusive, las obliga a mendigar para no morirse de hambre.

En la serie criminal, el $49 \%$ de las demandas son consecuencia de robos. Esos atentados a la propiedad conciernen sobre todo al ganado (abigeato) -el $28 \%$ de los casos- pero encontramos también estafas, desfalcos, deudas no pagadas, tierras indebidamente ocupadas -el $21 \%$ de los casos-. Todos esos problemas, y sobre todo las reacciones que suscitan entre los agraviados, revelan además entre éstos un arraigo significativo y muy neto de la propiedad individual, así como de los sentimientos que giran alrededor de su defensa.

Las violencias físicas también son numerosas -el $25 \%$ de los casos- y oponen dos veces de cada tres un indigena a otro. Hay que señalar igualmente 34 homicidios o tentativas de homicidios (el $12 \%$ de los casos) complicados a veces en brujería. ${ }^{11}$

Los asuntos vinculados con problemas o agresiones sexuales son, al revés, excepcionales y sólo parecen haber llegado al conocimiento del protector cuando los habian

10 Ver. Bernard Lavallè "Divorcio y nulidad de matrimonio en Lima (1651-1700), la desavenencia conyugal como indicador social" Revista andina, IV, 2, 1986, pp. 427- 454.

"Ver la queja de José Peregrino (1786) indio de la guaranga de Bambamarca a raíz del asesinato de su hijo. Los criminales lo habian matado estando ebrios, instigados por un brujo cuyas prácticas se describen detalladamente. El interrogatorio había de llevar a la inculpación de otro personaje ya encarcelado por idolatría. 
Presion colonial en Cajamarca

acompañado sevicia grave o la muerte. Algunos problemas de adulterio terminados de manera trágica se convierten así en criminales, pero otros llegaron a clasificarse así a raíz de encadenamientos inesperados o desgraciados. Pablo Caxa fue encarcelado durante dos meses en 1787 por haber mordido, durante una riña conyugal, el dedo de su esposa, que tuvo después que ser amputado... En 1796, Micaela Guamán, oriunda de Huambos, puso demanda contra D. Antonio Vargas, dueño de la estancia del Suro, porque éste la había convencido de que viniese a trabajar para él con su esposo. Poco después, a fuerza de ruegos, $D$. Antonio la había enamorado y llegó a conseguir sus fines hasta el día en que el marido informado, - cansado de la situación, se consiguió también una concubina. Las cosas se habian puesto feas y el estanciero, para poner orden en las relaciones de sus trabajadores, había roto relaciones con Micaela $y$, no pudiendo reestablecer la paz entre marido y mujer, les había propinado a cada uno una sonada golpiza por la cual se quejaban.... ${ }^{12}$

No pocas veces, las demandas criminales provienen de indios de los pueblos que denuncian a sus alcaldes que les pegan, abusan de su trabajo o les perjudican en sus intereses. En 1811, Asensio Santiago, de San Marcos, de vuelta de un viaje, se entera de que su mujer (según él perteneciente a "la clase española" pero de hecho "mestiza real" como iba a probar la encuesta) se había visto obligada por los alcaldes a asistir a la doctrina como si fuera una india cualquiera, lo cual era deshonroso para ella y no podía, como aducía su marido, sino causar perturbación en el pueblo.

12 "... inducido (D.A. Vargas) de una vehemente pasión ilícita, persuadió a mi parte hasta haber perpetrado en ella adulterio y como por su sexso persuadida, allándose como sierva debajo de la potestad de varón constante, no pudo evadirse de acceder a los apetitos carnales de aquel incidente". 


\section{Bernard Lavalue}

A menudo, los dos alcaldes de un mismo pueblo se denuncian mutuamente ante las autoridades coloniales. En 1785, el segundo alcalde de la Asunción, D. Antonio Carhuarayco reprocha al primero sus agresiones físicas, sus insolencias, su ignorancia escandalosa y hasta su desconocimiento del castellano... Tres años más tarde, el primer alcalde de San Marcos ofrecía a propósito del segundo un retrato inesperado tratándose de un responsable municipal. ${ }^{13}$

La mayoría de veces, el protector demostraba mucha moderación y bastante tino para reducir a justas proporciones y concluir por las buenas las diferencias nacidas de motivos nimios y que, por esas cosas de la vida, habían pasado a mayores: una pelea de borrachos por un real, terminada a sus instancias por una reconciliación general, ${ }^{14}$ una riña por un cirio robado que el demandante conservaba preciosamente para el Corpus, una herida causada imprudentemente por unos chiquillos que jugaban a la corrida imitando los pitones del toro con pencas de maguey. Cuando era necesario, el protector no vacilaba en levantar la voz para

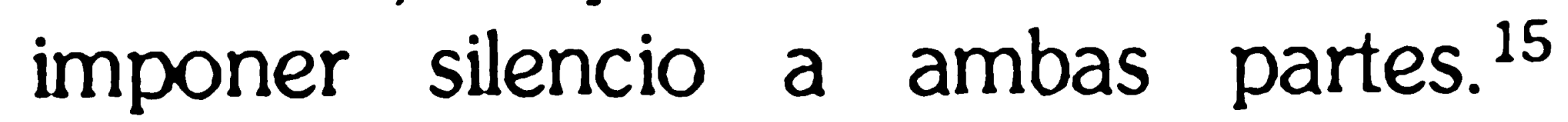

13 "... yncesante hebrio, público ladrón, atrebido setista, notorio reboltoso cebdicioso, tirano, rapiñante, infiel de ningún sigilo, usurpador de lo ajeno, enemigo de la paz, ynobediente de la real justicia..."

14 "hemos celebrado concordia de amistad y transigiéndonos urbanamente, premeditando con cristianas reflexiones las incomodidades, gastos que ocasionan los litigios en perjuicio no sólo de los intereses sino también del sosiego y tranquilidad que entre católicos debemos observar, mediante la paz y buena voluntad que el supremo criador nos recomienda por su evangelio (1799).

15 Supuesto que uno como otro de los litigantes eran cómplices por sus malos procedimientos $y$, lo que es más, parientes muy inmediatos en quienes no devia reynar ninguna desavenencia ni la continuación de un litis que por sus consecuencias trae consigo los mayores gastos y atrasos, que compareciesen ante mi y que se cortase de raíz una materia $\tan$ idiota, lo que verificó". 
Presion colonial en Cajamarca

El archivo del protector no se reduce, ni mucho menos, a ese tipo de asuntos que, además, pueden servir para reconstruir una especie de crónica escandalosa de una pequeña región provinciana. Más allá de lo anecdótico, tenemos alli un acervo muy útil para tratar de entender, a nivel cotidiano, la lógica y las expresiones de la violencia campesina de la que Ward $A$. Stavig ha demostrado el significado y alcance en esa misma época para las regiones cusqueñas de Quispicanchis y de Canas y Canchis. ${ }^{16}$

Este archivo presenta en efecto un interés de primera magnitud en la medida en que buena parte de sus expedientes conciemen en efecto, y revelan, las relaciones conflictivas entre españoles $e$ indígenas, más precisamente las quejas de éstos contra aquellos. Gracias al espacio crítico que ofrecía la actuación del protector, a través de las vivencias cotidianas aquí denunciadas $-y$ ésta es su originalidad- por aquellos que las habian padecido, penetramos hasta el mismo corazón de las tensiones suscitadas por una relación en esencia conflictiva.

Algunos casos en que los españoles no vacilaban en ejecutar su propia justicia sin esperar la del rey, y en que ejercian lo que consideraban como su derecho inalienable y esencial de superioridad y castigo, son reveladores por su carácter espontáneo -y su repetición- del lugar implícitamente reservado al indígena en ese contexto psicosocial.

En 1800, José Valera, un mercader español de Cajamarca, hizo confesar con palos y luego ató al rollo municipal al hijo de un indio al que acusaba de haber robado dos ponchos durante una corrida, lo cual el padre del cholito negaba absolutamente. Ese mismo año, un tal José Bringas sospechaba por desfalco de dos cobradores

${ }^{16}$ Ward A. Stavig "Violencia cotidiana de los naturales de Quispicanchis y Canas y Canchis en el siglo XVIII", Revista andina, III, 2, 1985, pp. 451-468. 


\section{Bernard Lavalle}

de diezmos. Los prendió y, para que confesasen, les aplastó un dedo con un percutor de escopeta. En 1810, los alcaldes indigenas de Celendín pusieron demanda contra los españoles del lugar, dado que éstos, acusando a una india de abigeato la habian castigado, sin llevarla ante la justicia, de la manera más cruel: confiscación de sus bienes, destrucción de su casa y dispersión de su familia. ${ }^{17}$

Un examen más detallado de estos casos muestra nítidamente que más allá de meras desavenencias individuales significativas, por supuesto, del nivel de violencia cotidiana originada por el desprecio de los dominantes y más allá del concepto implícito que éstos se formaban del indio, estamos en presencia de conflictos sin duda personales pero que, de hecho, provienen de la organización colectiva de las relaciones sociales articuladas alrededor de la hacienda.

Así, se descubre cómo José Bringas del que se habló más arriba no era sino mayordomo de la hacienda Huacariz de la que trataremos más adelante. D. Juan de la Oliva y D. Juan Manuel de Arribasplata denunciados en 1793 por el pueblo de San Pablo por haber pegado a una india $y$ a su nieto de cuatro años que habían protestado porque los dos hombres habian llevado su ganado a pastorear en los cultivos de la pobre mujer, son en realidad el mayordomo y un familiar del dueño de la hacienda Tumbadén.

17 "En cuyo asunto resolbieron por sí, como por sentencia definitiva, rematando los bienes de la india, demoliéndole su casa y despojándole de sus hijos para entregarlos a varios españoles por vía de vendidos según todo consta de los autos como también no haberse justificado el delito de la india"

A propósito del tráfico de niños raptados a sus padres $y$ vendidos en la ciudad o en las haciendas de regiones a veces muy remotas, es de señalar que muchas demandas indigenas aluden a esta práctica, lo cual muestra bien que el caso citado en el texto dista mucho de ser excepcional. 


\section{Presion colonial en Cajamarca}

En 1797, dos alcaldes y el común de Contumazá se quejan del teniente de milicia D. Matías Díez. ${ }^{18}$ Con motivo de la fiesta del rosario, el primer alcalde había mandado a uno de los criados de $\mathrm{D}$. Matías que ayudase a la construcción de los altares que, según la tradición, adornaban la plaza. Ante la negativa rotunda, el edil le había propinado tres latigazos. Preso de loca cólera, el teniente había pegado al alcalde, lo había insultado y abofeteado en público. ¿Mera prueba de un carácter violento acostumbrado a considerar a los indios, cualesquiera que fueran, como seres apenas humanos? ¡Sin duda! Pero el resto del expediente nos revela que un antiguo contencioso oponía D. Matías al pueblo a propósito de la posesión de ciertas tierras aledañas, motivo por el cual el teniente, a pesar de los llamamientos de los alcaldes en repetidas circunstancias, prohibía a "sus" indios que fueran a oír misa en Contumazá.

Durante el período investigado, más de 70 expedientes que conciemen a unas cuarenta haciendas fueron estudiados por el protector. Algunas de estas propiedades que ya habían suscitado quejas entre sus trabajadores en épocas anteriores vuelven a aparecer con cierta regularidad: Huacariz (nueve veces) Matará y Callancas (cinco), Porcón, Chumbil y Huacraruco (cuatro).

En más de veinte casos, se trata de litigios relativos a pago, o no pago, de salario, sea que el dueño $o$ su mayordomo no hubiese devengado las cantidades prometidas, sea que no diera absolutamente nada. Los reclamos comprenden no pocas veces períodos largos, algunos meses, pero también varios años: en 1815, Pedro Olmos, de la hacienda Sondor, exige el salario correspondiente a nueve

18 "Hombre a la verdad odioso a toda la república, bolinista y voluntario que no distingue respetos a ninguna clase de personas por la mucha soberbia que le acompaña, suponiéndose más de lo que se merece con ser sólo teniente". 


\section{Bernard Lavalle}

años de trabajo, seis en el obraje y tres como peón agrícola; en 1797, Santiago Mendoza, tributario de la guaranga de Chuquimango se presenta ante la justicia para que la hacienda Tumbadén le cancele lo debido por diez años sin sueldo $y$, en 1809, Miguel Marcelo denuncia la chacarilla Ajoscancha donde había servido doce años como alfarero sin cobrar nunca nada...

Los litigios se originan también en la manera de efectuar los cálculos. En 1797, Francisco Vingo, agregado de la hacienda Chaquil, pide que se le revise las cuentas de lo cobrado durante los últimos trece años, dado que durante todo ese tiempo le habían pagado como mero pastor cuando, en realidad, había trabajado como conductor de rebaño (puntero) y por lo tanto merecía dos veces más.

Asimismo, los indígenas denuncian la arraigada costumbre de los hacendados que consistía en restarles del salario los daños y pérdidas padecidos por el ganado. En 1810, Andrés Rayco y Nicolás Villa, de Llacanora, se quejan de $\mathrm{D}$. Leonardo Arteaga, de Chiclayo, que los había contratado para guiar 130 puercos de Cajamarca a la costa y no los había pagado, arguyendo la muerte de varios animales. El año siguiente, Luis Chicoma denuncia a su amo D. Nicolás García que se niega a darle el dinero prometido porque algunas reces que vigilaba habian desaparecido. Ya anteriormente, Luis Chicoma se había visto obligado a vender dos bueyes suyos para compensar la pérdida de doce carneros y su hijo había huido por no querer soportar las consecuencias de la muerte de un verraco.

La mayoría de veces, estas quejas emanan de individuos, pero no pocas también son formuladas de manera colectiva, lo cual parece significativo. El conjunto de los indios de una hacienda se presenta entonces ante la justicia de manera solidaria, en particular en el momento de la transferencia de las propiedades por herencia. Sin duda escarmentados, temían que el nuevo dueño no quisiera aceptar 
Presion colonial en Cajamarca

las deudas de su predecesor. Tal fue el caso de los sirvientes de la hacienda Culquimarca, en 1790, que exigian la cancelación de las cuentas del anterior propietario, $\mathrm{D}$. Donato Bobadilla, o seis años más tarde de los de la hacienda Tumbadén que inician una acción judicial contra la familia de D. Fermando de la Oliva al anunciarse la puesta en subasta del fundo.

En general, en casos de este género, los indigenas no eran desoídos. Incluso se puede escribir que éste era el tipo de litigio en que se los atendía positivamente con más frecuencia. Los mayordomos recibian orden de presentar, de ahí a pocos días, los libros de tareas $y$ socorros donde tenían que apuntarse las faenas y salarios correspondientes a cada trabajador. De no hacerlo, eran condenados a pagar a los indios lo que se les debía en presencia de un comisario que se movilizaba hasta la hacienda.

Las cantidades sancionadas por la justicia eran, por lo común, bastante cercanas a las que reclamaban los demandantes, pero también podian ser revisadas por la justicia de manera transaccional.

El contraataque de las haciendas consistía entonces en argüir que los sirvientes también estaban endeudados para con sus amos. Esto, por lo menos, les permitía dar largas, a veces durante años, al asunto con la esperanza de que los demandantes se cansaran y desistieran de su propósito.

$\mathrm{Si}$ dentro de las haciendas las quejas son, como hemos dicho, en general individuales, pasaba al revés cuando los pueblos tenían que defenderse contra los procederes de los hacendados, de sus mayordomos o de sus guardaespaldas. Hemos sumado asi unos veinte casos en que los alcaldes, en nombre del común, denunciaban abusos de los terratenientes. 


\section{Bernard Lavalle}

En el origen de estos roces, encontramos a menudo problemas de linderos o derechos de pastoreo controvertidos. En otras partes, es la voluntad expansionista de las haciendas a expensas de los pueblos la que conduce ante la justicia a los campesinos exasperados de ver que los dueños se aprovechaban de su ignorancia, aislamiento y desvalimiento.

En 1799, el pueblo de la Asunción inicia una acción jurídica contra la hacienda Campodén que le ha quitado dos pedazos de tierra, una en las jalcas y la otra en el valle (en temple). Sin embargo, los derechos del pueblo habían sido confirmados poco tiempo antes de manera oficial, pero los hacendados, muy despectivamente, no habían acatado la decisión "sin más motivo -escribía el protector- que la humilde esfera de su naturaleza de indios siempre perseguidos del espotismo (sic)".

En 1810, segura de sí misma por el mero hecho de ser española (valida del carácter de española) Da. Faustina Fernández Briceño, dueña de la hacienda Muzadén, había propuesto a los indios una transacción, pero consistía en venderles las tierras que reclamaban y que según aducían, siempre habían sido de ellos. ${ }^{19}$

Los conflictos surgían también por el control del agua de vital importancia. En 1800, los indios de la Paccha demandan al mayor $\mathrm{D}$. Joseph Isla que, para regar sus tierras, acababa de cegar una acequia de la que se valía el pueblo y que cuidaba mucho. En 1817, el pueblo de San Gabriel de Cascas protesta contra el mal reparto del agua acaparada en su detrimento por algunos españoles

19 "Intenta despojarles $y$ venderles lo que propiamente es dellos. Más nada hace judicialmente sino que, haciéndole juez y parte, confunde a los miserables labradores indios, escasos de razones, tanto que con autoridad ha conseguido con amenazas de cárcel que [...] le otorguen una obligación de 150 pesos [...] dándole un colorido de tranzación". 


\section{Presion colonial en Cajamarca}

que, por preciarse de ser caballeros, desprecian rotundamente a los indios ("menosprecian su nacimiento").

La situación inversa, aunque no tan frecuente, existía también. En 1788, D. Juan Esteban de Arriaga, vecino de Chiclayo, denuncia al cacique, a los principales y al común de Tocmoche. Desde hacía doce años estaban ocupando ilegalmente parte de su hacienda de San José de Yagua. D. Esteban, por otra parte, no había esperado la decisión de los jueces para imponer lo que consideraba como sus derechos. En su defensa, los indios indican cómo, para ahuyentarlos, los caporales de la hacienda, insultándolos y llamándoles ladrones, habían quemado sus chozas, espantado el ganado $y$ pisoteado con los caballos las sementeras.

Las tentativas de ese género no siempre se deben a españoles. En algunas, se acusa a los mestizos, signo sin duda de la presión demográfica y social de este componente étnico en aquella época, pero también de una convivencia conflictiva desde mucho tiempo atrás entre indios y castas de la que la vida cotidiana ofrece numerosos y diversos ejemplos.

En 1804, el común de San Bernardino lo dice claramente:

"Oy, al paso que crece nuestra necesidad, crece también la codicia de las gentes de castas, especialmente aquellas que nos son vecinas, largamente nos infieren cada día mil perjuicios que no podemos evitar por no tener los recursos inmediatos, y mientras ocurrimos al señor juez de provincia acabarán con nosotros...".

Esto podia llevar hasta a enfrentamientos violentos. En 1733, tres familias indígenas del común de Yanayaco se habian dirigido al protector para denunciar a seis mestizos que "por su propia autoridad" y apertrechados como para una cacería ("armados en chaco") los habian expulsado 


\section{Bernard Lavalle}

de unas tierras cuya propiedad hasta la fecha no se les había discutido.

En 1807, un caso del mismo tipo fue bastante sonado en el mundillo cajamarquino dada la calidad de las víctimas. D. Antonio Pérez Yupanqui y D. Patricio Pérez Yupanqui, descendientes -según indica el apellidode los Incas, como escribano y alguacil mayor habían ido a expulsar unos mestizos instalados en tierras indígenas cerca de la hacienda Huacariz. Después de negarse a obedecer, los mestizos habian pasado a mayores, gritando "mata y mata a estos indios" y pegándoles, lo que motivaba la demanda muy sentida de ambas víctimas.

Los litigios no forzosamente eran suscitados por anexiones violentas. Los pueblos indigenas se muestran en efecto muy vigilantes frente a cualquier tentativa de penetración y de instalación pacífica, pero solapada, de los españoles o de los mestizos venidos de fuera. En 1800, en nombre del común, el procuradór de Sañta Ana, pueblo anexo de Guzmango, pone demanda al alcalde Bernardo Julca, por haber aceptado que un tal Eduardo Benítez, de Cascas, le alquilase tierras de la comunidad sin hablar del caso con los demás cabildantes como lo exigía la tradición. En 1807, el común de San Miguel de Pallaques pide desalojar a un Manuel Barbosa acusado de haberse arreglado con un indio para que éste le vendiese sus parcelas.

Diez años más tarde, los campesinos de Sorochuco denuncian a $\mathrm{D}$. Juan de Apéstegui que acaba de comprar tierras -hasta entonces pertenecientes a un comunero del pueblo- y quiere comprar más aún para poner en ellas a una familia de trabajadores, lo cual, como bien lo denunciaban los indígenas, no era ni más ni menos que el inicio de una hacienda en el mismo seno de la comunidad.

Por lo que hemos podido comprobar, en casos de este tipo, la justicia española manifestaba una vigilancia bastante estricta y, la mayoría de veces, los jueces sentenciaban en favor de los indígenas tanto más cuanto que, en el 
Presion colonial en Cajamarca

particular, la legislación colonial era precisa y la jurisprudencia bien establecida.

Esto no significa que las soluciones fueran siempre fáciles de encontrar, en particular cuando las inspecciones periódicas de la administración (remesuras) sancionaban oficialmente, gracias a complicidades y cohechos, las modificaciones catastrales en detrimento de los indios.

De todos modos, en este tipo de conflictos, los que ocupaban de manera precaria o ilegal los terrenos exigían una indemnización por las mejoras que habían hecho y que, por supuesto, la parte adversa se negaba rotundamente a pagar o trataba de minimizar. En 1801, el común de Sañ Gabriel de Cascas no quería aceptar las mejoras exigidas por una tal Da. María Núñez y su hijo en la medida en que, según los indios, se trataba tan sólo de una labranza y de "un ranchito ya bien maltratado", sin contar que la intrusa los había hecho tan sólo en provecho suyo ("si rompieron las tierras fue en obsequio de sus utilidades en los cultibos y cosechas que tiene aprovechadas").

Obligados, sin embargo, a pagar 56 pesos por las supuestas mejoras, los campesinos exigieron entonces a su vez el precio del alquiler de las tierras $(6$ pesos al año) y un derecho de pastoreo de dos pesos por cada res que había mantenido alli Da. María...

Así se entiende cómo algunos pleitos de este tipo durasen años en los meandros de los trámites judiciales $y$ de la tenacidad silenciosa, pero sin flaqueza, de los indigenas. Así, lo que en 1788 oponía a D. Juan Esteban de Arriaga, dueño de la hacienda San José de Yagüe, $y$ al pueblo de Tocmoche duraba en realidad desde... 1659. Ya en 1678, una decisión del virrey había condenado a los indios, intimándoles guardasen sobre esto "un silencio perpetuo", pero el lector recordará que, cuando D. Juan Esteban había reactivado los trámites, el pueblo ya había recuperado "sus" tierras sin ruido, pero de hecho, desde hacía doce años. 


\section{Bernard Lavalue}

Del conjunto de quejas indígenas resalta nítidamente el hecho de que, en la hacienda, la compulsión y la violencia constituyen la base de las relaciones sociales. Las más de las veces, son los mayordomos y el personal subaltemo a quienes se reprochan las sevicias más graves. Por no haber cumplido con su tarea en el obraje, el indio José Céspedes fue condenado por el mayordomo Fructuoso Gastelmendi a 50 latigazos al cabo de los cuales, incapaz de andar, José había sido arrastrado en el suelo lo que le había dejado las secuelas más terribles ${ }^{20} \ldots$

No escaseaban las amenazas de muerte $y$, a veces, había verdaderos asesinatos. En 1786, Juan Guamán, caporal encargado de la labranza en la hacienda Santa Mónica de Huacraruco, mata a palos a Francisco Quiliche que se negaba a trabajar más tiempo y regresaba a casa pretextando que era un día festivo. En 1799, Pablo Cóndor Luicho, de la hacienda Santa Ursula, que pertenecía a Juan Martínez de Goicochea demandaba al mayoral Vicente Guamán que, valido de la protección del amo, hacía reinar el terror en la hacienda y cometía toda clase de abusos. $^{21}$

Lo peor, sin embargo, quedaba por venir. Vicente Guamán había castigado a la hija del demandante, la había atado delante de su puerta y le había pegado a tal punto que murió tres semanas más tarde con horribles sufrimientos. Lo más horrendo era que la niña sólo tenía seis años...

Por lo tanto, no ha de extrañar el hecho de que entre los casos de sangre de los que tenía que tratar

20 "... de cuyas resultas se halla demolido un compañón y el miembro viril [por] mellársele aquellas partes tan delicadas".

21 "Disfruta el favor $y$ permiso del hacendado; para estos excesos se ha tomado más autoridad de la que su constitución índica le permite para con sus compañeros. El favor le tiene constituido en la actualidad de mandón, alcalde y fiscal de sus hermanos". 


\section{Presion colonial en Cajamarca}

la justicia de Cajamarca algunos eran denunciados por los dueños de haciendas y tenian como víctimas a los mayordomos o caporales heridos o muertos por indios exasperados. Así, en 1790, Julián Oliva llevado ante los jueces por el asesinato de un mayoral de la chacarilla San Lucas; Antonio Minchán, implicado en heridas de consideración a Estanislao Carhuaguatay que contrataba, de manera no siempre voluntaria al parecer, a los futuros trabajadores de la hacienda de su amo (1789).

A menudo, esas situaciones violentas estaban vinculadas en las haciendas al deseo de captar o conservar, de cualquier manera que fuese, a la mano de obra indígena que, por lo visto $y$ en función de las maniobras denunciadas, era entonces algo muy precioso, quizás más aún que la misma tierra. Sencillamente pero con perspicacia, los indígenas de la hacienda Montán, en la provincia de Huambos, lo declaraban claramente en 1782 cuando pedian con insistencia al protector que no autorizase la venta de la hacienda a un tal D. Francisco Arroyo y Alvarado que, hasta entonces, era inquilino de la propiedad y se había mostrado siempre muy duro con ellos:

"... que nos ha de comprar -escribían- que la hacienda no quiere por sus tierras sino por nosotros que somos sus esclavos. Por eso no nos paga nuestro trabajo".

Los campesinos reclaman, por ejemplo, porque el pongueaje, que normalmente formaba parte del trabajo en la hacienda, se practicara también a beneficio de españoles que no eran hacendados. En 1809, Manuel Ruiz, indio tributario del pueblo de San Marcos demandaba a Agustín Gil, cobrador de impuestos, que lo había ocupado unos veinte días como pongo, esto es sin salario. EJ mismo año, los comuneros de Ichocán protestaban porque 


\section{Bernard Lavalue}

sus alcaldes solian mandarles como pongos a casa de los curas de la región. Exigían que se les tratara como sirvientes españoles, esto es con un salario en dinero pacjado directamente y no a los alcaldes a los que se debería llamar la atención para que cesasen sus abusos ("a quienes se aperciba la no inquietud de sus nacionales").

Del mismo modo, los períodos de trabajo obligatorio, la mita, daban motivo a muchos abusos. Dos casos de 1810 son ilustrativos al respecto: Un año después de haber sido mitayo de la hacienda Chaquil, Manuel Guamán fue detenido un día y llevado atado por los mayorales de la estancia Sangal pretextando, sin fundamento al parecer, que Manuel había de cumplir sin tardanza un nuevo periodo de mita... Melchor Cóndor, de la guaranga de Malcadén, se quejaba él de que la hacienda Sondor lo hubiera retenido trece meses en vez de los seis previstos. $\mathrm{Si}$, por fin, había podido escapar, su madre, ella, seguía cautiva en la hacienda.

Para conseguir mano de obra, los hacendados recurrían a métodos muy diversos. Cuando una campesina que pertenecía a una hacienda se casaba con un indio libre no pocas veces los dueños trataban de presionarla, incluso con violencia, para que ésta se quedara a su servicio con el marido, incrementando así la mano de obra de la que disponian. En 1788, Manuel Ramos, de la guaranga de Pomamarca, era inquietado por dos hacendados del pueblo de la Asunción que deseaban vincularlo a su propiedad a raíz de su casamiento con una de sus sirvientas cuya hermana secuestraban a manera de presión. Más dramático fue el caso de Flora Cuñi, de San Miguel de Chalaques. Hija de mitayos que se habian quedado de su propia voluntad al cabo de su período de trabajo en la hacienda de D. Joseph Florencio Flores, la joven se había casado con un indio libre y había ido a vivir con él. El dueño, considerando que ella formaba parte en adelante de "sus" indios había ido a rescatarla y había 


\section{Presión colonial en Cajamarca}

regresado con ella a la hacienda a viva fuerza y cargándola de grillos. $^{22}$

El asunto había cobrado proporciones más dramáticas aún en la medida en que el bebé de la joven había muerto por los maltratos. Flora había vuelto a huirse y los alcaldes del pueblo de su marido la defendian activamente en su libertad $y$ derecho.

La diversidad de los estatutos jurídicos de los trabajadores en la hacienda, la complejidad o ambigüedad de ciertas situaciones personales, permitían a los dueños interpretaciones que todas redundaban en provecho suyo $y$ les llevaban a incluir definitivamente a los campesinos entre sus siervos.

A menudo los amos consideraban que los mitayos concedidos por la administración, por el mero hecho de volver regularmente a la hacienda durante años seguidos, llegaban a formar parte de ella de manera formal y definitiva. En 1799, el común del pueblo de Jesús denunciaba a D. Simeón Vasquez por haber incluido dentro del número de los matriculados de su hacienda a unos campesinos de la comunidad de Palturo que eran sus mitayos desde hacía cinco años. Los demandantes precisaban que era ésta una práctica corriente de los dueños cuando se efectuaban las revisitas. Seguro de su derecho y de la importancia del asunto, el común del pueblo no vaciló en elevar el caso hasta la audiencia de Lima.

En un documento del 20 de julio, el fiscal de ésta estigmatizaba la matriculación fraudulenta de indios libres que cualificaba como "un ramo pingüe de negocia-

22 "El señor dueño de la hacienda (...) dice que respecto de ser los indios sus padres de la hacienda, ella también debe ser esclava de ella. Por este motivo, la apresó dicho caballero y llevándola con prisiones a la hacienda..." 


\section{Bernard Lavaue}

ción", dejando entender así que los jueces de revisitas no estaban exentos de reproches en tales manejos.

Los quinteros, esto es los indios que se alquilaban libremente en las haciendas al terminar su periodo de mita, también eran considerados a menudo por los dueños como siervos de la hacienda. Lo mismo pasaba con los forasteros, esos indios oriundos de otras comarcas o sencillamente de una comunidad distinta de aquella en que vivían y gozaban alli de un estatuto especial. Los dueños trataban de vinculárselos definitivamente, sea arguyendo que figuraban en la lista oficial de los matriculados de su hacienda -pensando que los alcaldes no los reclamarían porque los forasteros estaban a menudo mal considerados en los pueblos- sea considerándolos como mitayos cuando normalmente estaban exentos de semejante obligación. Era, además, uno de sus pocos privilegios como explicaban dos de ellos, Fermín y Miguel Guacha en $1808 .{ }^{23}$ El primero acababa de ser designado como mitayo en la hacienda de Combayo y su mujer había sido llevada a viva fuerza al obraje, según una práctica abusiva muy arraigada en la región ("como continuamente acostumbran los hacendados de aquella provincia").

Para obligar a que los padres recalcitrantes se quedasen a su servicio, los hacendados no vacilaban en retener a los hijos, de rehenes, en alguna manera. En 1797, Santiago Angasua, de la Asunción, denunciaba a D. Francisco de la Serna, dueño de la hacienda Santa Clara de Matará que tenía cautiva a una de sus hijas y la obligaba a trabajar con grillos para que no huyera. Algunos años más tarde, en 1803, los hermanos Rafael $y$ Juan Goycochea, de San Marcos, demandaron a D. Pedro de la Carrera que, no contento con pegarles cruelmente,

23 "No [gozamos] de tierra de repartimiento ni otras comodidades que logran los demás indios de esta república, y tanto por ello como por ser de clase de forasteros quinteros, [estamos] exentos de servidumbre de mitayos según lo últimamente resuelto por la superioridad". 


\section{Presion colonial en Cajamarca}

había raptado a la hija de uno de ellos. La habían encontrado al cabo de cuatro meses de búsqueda, porque $\mathrm{D}$. Pedro la había mandado a Cajabamba.

Entre los medios de presión empleados por los hacendados, se divisa muy bien gracias a las quejas indigenas que la deuda ocupaba un lugar preferencial.

Ya en 1706, el indio García Malcachín, de Cutervo, que había sido peón por siete años en la hacienda de Bartolomé Mendoza, demostró claramente el mecanismo, ${ }^{24}$ pero el sistema tenía facetas múltiples y sobre todo consecuencias dramáticas para sus víctimas. La menor cantidad podía desencadenar un proceso casi irreversible. En 1788, Diego Rupacho, un quintero, cuenta cómo durante su período de mita había pedido prestados 6 pesos y 4 reales al dueño de la hacienda Chaquil, y había llegado a un acuerdo con éste para servirle, a manera de pago, como hortelano con los cinco miembros de su familia. Pero el tiempo había pasado y hacía ya siete meses más de los previstos que toda la familia trabajaba sin salario. Por si fuera poco, el dueño de Chaquil pretendía inclusive que todos ya eran matriculados de la hacienda. ${ }^{25}$ Otro ejemplo revelador es el de Eusebio Cerdán, un quintero de San Marcos, a quien el hacendado de San Lorenzo de Matará había adelantado una cantidad a cambio de conservar hasta el pago al hijo del endeudado. Al cabo de dos años, Eusebio protestaba porque el joven seguía en la hacienda sin poder abandonarla, lo cual justificaba

24 Después de recordar las "dos mil vejaciones de agravios" aguantadas a lo largo de los años, añadía:

"Llega a que nọ les permite a todos los indios que le sirven que siembren para su sustento de sus mujeres $e$ hijos $y$ hace que todos se mantengan con lo que les da de sus despensas a precios exorbitantes con la mira de tenerlos siempre empeñados y sujetos a servidumbre".

25 "El referido caballero por ser estanquero y arrendador de tabaco en polvo dice no hay quien me saque de su poder como si fuera su esclavo". 


\section{Bernard Lavalle}

el mayordomo aduciendo que el padre no había reembolsado todavía integramente el dinero prestado.

$\mathrm{Si}$ los hacendados trataban de muchas maneras, inclusive las más condenables, de conservar y vincular a los trabajadores indigenas, éstos se aprovechaban de la menor ocasión para escapar legalmente. En 1796, Victorino Pérez había utilizado la última revisita para hacerse matricular entre los sueltos de San Pablo, cuando hasta entonces era porcionero de la hacienda Chumbil que pertenecía a los Verasátegui. Respaldado por esa decisión, Victorino había cometido la imprudencia -descarada según sus examos- de ir a visitar a su padre que se había quedado en la hacienda. Para castigarle, lo habian apresado, pegado con las botas en el pecho $y$ colgado de los pies. En 1804, el común de Contumazá pidió que se le enseñara la última matrícula para poder contestar a la "hostilidad" de los hacendados de Chota y Catudén que exigian "con violencia" que se les mandasen unos mitayos destinados, según decían, desde tiempos muy remotos a sus propiedades, lo cual, por supuesto, negaba el común rotundamente. En 1808, el cura D. Pedro de Herrera, dueño de la hacienda Saparcón presentó una demanda porque varios de "sus" indios con sus familias habian aprovechado la última revisita para irse a matricular en el pueblo vecino de San Marcos y así habían huido de su antiguo estatuto.

A veces, inclusive, había discusiones muy duras entre los amos en cuanto a sus respectivos derechos sobre tal o cual campesino. En 1793, Estefanía Malquipoma, oriunda de Chetilla, había sido apresada por el inquilino de la hacienda Secsecmayo a donde había ido para visitar a un conocido. Dicho inquilino aducía que Estefanía era una de sus mitayas huida. Esta sólo había podido regresar a su casa -después de una serie de latigazos en las nalgas- cuando intervino muy enérgicamente el licenciado D. José Justo Ramírez que dirigía la hacienda de la Cadena donde Estefanía trabajaba con su ma- 


\section{Presion colonial en Cajamarca}

rido. Tres años más tarde, Mateo Llamoga, matriculado de la hacienda Culquimarca del pueblo de la Asunción era objeto de interminables disputas entre dos hacendados. Quince años atrás había sido dado (condonado) con su mujer e hijos por el dueño de la hacienda a su hermana Da. Juana ("para que le sirviese como criado propio"). El heredero del donante exigía ahora la vuelta de Mateo y su familia, lo cual Da. Juana negaba enérgicamente.

Entre las numerosas preguntas que suscitan estos documentos, una de las más fundamentales es, sin lugar a dudas, qué valor -esto es qué poder- reconocían los indios al protector $y$ a la justicia española en aquello que estaba relacionado con sus problemas.

Se impone una primera advertencia. En cuanto a asuntos criminales, los más graves pues, constatamos un aumento constante del número de quejas: 6 de 1690 a 1699, una media de unas 12 cada diez años entre 1700 y 1740, unas 20 por decenio de 1740 a 1770 , más de 30 entre 1770 y 1779 , más de 20 durante cada decenio del período 1780-1820...

¿Será éste el resultado de una mejor conservación de los expedientes conforme iba pasando el tiempo de una agravación de la presión colonial que acarreaba una multiplicación de los abusos, de una toma de conciencia cada vez más aguda y combativa de sus derechos por parte del mundo indígena? Sólo análisis mucho más finos que tomasen en cuenta otros parámetros del contexto económico y social de Cajamarca, o del Perú en conjunto, permitirian quizás contestar de manera segura.

A primera vista, el número importante y creciente de las quejas presentadas al protector, es, si no una prueba, por lo menos un signo de que los indios confiaban de alguna manera en sus desvelos y en el resultado de su intervención. ¿Cómo explicar en efecto que hubiesen seguido trasladándose hasta Cajamarca para quejarse si hubieran estado convencidos de antemano y por experiencia 


\section{Bernard Lavanf.}

de la vanidad de sus esfuerzos y de la ineficacia del protector? No hay que olvidar que si muchos expedientes concemian casos relativos a problemas nacidos en las inmediaciones de la capital regional, un fuerte porcentaje provenía de las comarcas más remotas de la subdelegación y habían exigido recorridos de varios días, por lo tanto una voluntad y una perseverancia que, sin lugar a duda, bien esperaban no salir defraudadas.

Tampoco hay que olvidar que en el contexto regional de la época, demandar a un español o a un criollo, cuanto más si era poderoso, no era cosa sin consecuencia. Una vez vuelto a su pueblo, o a su hacienda, aún respaldado por una decisión favorable de la justicia pero muy lejos ya de ésta, el demandante estaría bastante desvalido ante aquel a quien había denunciado. Algunos expedientes lo demuestran sobradamete. En 1711, Francisco Limay, de la guaranga de Chuquimango, había conseguido que su patrón, que no le pagaba, compareciese en Cajamarca ante la justicia y trajera consigo sus libros de cuentas. Dicha orden le había sido comunicada por el teniente de corregidor. Teniendo que acatar y cumplir, el patrón, José Izquierdo, había montado en cólera y toda su ira se había ensañado contra Francisco Limay que había temido por su vida. ${ }^{26}$ En 1800 , a pocas semanas de intervalo, el protector tuvo que tratar dos casos relativos a un tal José Quispe del pueblo de Jesús. Había sido encarcelado, al parecer sin motivo valedero, por el dueño de la hacienda Yurac Pirca. Liberado por orden de la justicia después de una denuncia de sus familiares, tuvo que acudir al protector un mes más tarde porque el hacendado se había vengado obligando al hermano de José a trabajar gratuitamente y sometiéndole a toda clase de abusos. En 1812,

26 "Sin más motivo ni ocasión más que el haberle notificado dicho despacho y pedídole mis derechos [...] diciendo lo pagaría con el pellejo, dentráridose a la casa de su vivienda y arrancando espada y daga, salió a donde estaba con los dichos testigos a provocarme". 


\section{Presion colonial en Cajamarca}

dos campesinos de San Marcos demandaron a su cura que, furioso por una queja anterior contra él a iniciativa de los dos, les hacía la vida imposible.

Muchos casos que hemos encontrado prueban que en las haciendas los demandantes podian contar con verdaderas redes de solidaridad. ¿Cómo explicar, si no, que los casos de algunos indios encarcelados en tal o cual hacienda a veces alejada de Cajamarca, con grillos y cadenas, pudiesen llegar hasta el protector? Por supuesto, existía en algunos pueblos un procurador que servía de relevo al protector, y al parecer lo hacía eficazmente. En 1811, los alcaldes y el común de Chetilla pidieron y consiguieron el nombramiento de un procurador en el pueblo para que se ocupase de los problemas de la gente menuda con los hacendados que se negaban a pagarlos.

Para terminar con este aspecto, hay que añadir que hasta los siervos de las haciendas que estaban vinculados de manera prácticamente definitiva y no podian gozar de la solidaridad del común de los pueblos, como en el caso de los mitayos o de los quinteros, tenían sin embargo el ánimo y la esperanza suficientes de demandar a sus amos por problemas de violencia o salario, lo cual es tanto más significativo cuanto que estaban más expuestos a posibles venganzas.

De hecho, las quejas indígenas no dejaban exento a ningún sector del poder local o regional: los alcaldes de pueblo y los numerosos intermediarios del sistema colonial, como cobradores de impuestos o de diezmos, y encargados del cumplimiento de la mita. Del lado español tampoco nadie estaba exento: tenientes de milicia, curas, dúî̃̂̃ de de haciendas o estancias y hasta jueces, ya que en 1791, dos quinterós de! pueblo de Jesús demandaron... al propio juez territorial D. Marcos Fernández, también dueño de la hacienda Yurac Pirca. El funcionario más alto de la región, el propio subdelegado, no estaba exento de semejante riesgo. En 1788, Matías Guanipata inició una acción judicial contra su patrón, Juan de la Guisla 


\section{Bernard Lavalle}

Larrea, que le había encarcelado por la pérdida de algunas ovejas. Ahora bien, D. Juan no era sino el último corregidor de Cajamarca que se había quedado en su puesto en 1785 sólo que con el nuevo título de subdelegado. ${ }^{27}$ Al año siguiente, el alcalde de Chetilla demandó al subdelegado interino D. Fernando de la Fuente por diversos abusos de autoridad cometidos por éste.

Aún si detrás de semejantes quejas bien se podían esconder luchas y rivalidades entre diversos sectores del poder español, esto no quita que existían, y las rivalidades entre españoles no hacian sino utilizar estas quejas haciéndolas prosperar.

Por supuesto no es necesario insistir sobre las dificultades que obstaculizaban el paso de la justicia cuando ésta fallaba en pro de los indios. El poder de los hacendados y sus vínculos sociales, en particular, eran una terrible fuerza de inercia. En 1797, el indio Antonio Lima había denunciado a su amo, el dueño de la hacienda Huacariz. El caso había sido tratado normalmente; un comisario se había encaminado hasta la hacienda y había hecho su encuesta. Alli, había concluido con que el hacendado era inocente... porque los demás campesinos de Huacariz le habían declarado a una que Antonio Lima había calumniado al dueño... En idénticas circunstancias, otro comisario que había ido a investigar en la hacienda Huacraruco a raíz de la queja de un indio por graves maltratos escuchó por boca de los demás trabajadores que ni el amo, ni tampoco el mayordomo, castigaban nunca a nadie...

27 Para otras acusaciones contra ese personaje en la misma época a raíz de abusos contra los indios, ver John Fisher op. cit. p. 105. En 1802, el protector Manuel Fernando Soriano inició un trámite judicial contra el subdelegado por quejas de los indígenas a quienes no pagaba el trabajo y de los que exigía impuestos indebidos. lbid. p. 106. 


\section{Presión colonial en Cajamarca}

Incluso, a veces, la justicia era sencillamente burlada con el mayor descaro. En 1798, habiéndose iniciado un pleito contra el hijo del dueño de la hacienda Chumbil que había infligido graves sevicias a un criado indigena, cuando el comisario llegó allá para ejecutar la sentencia, el culpable había desaparecido desde hacía tres días $y$, por supuesto, nadie conocía su paradero. Como, además, no poseía nada personalmente no se le pudo hacer tampoco ningún embargo. Otro hacendado condenado a unos días de cárcel en Cajamarca, mandó decir que no podia dejar su propiedad antes de mucho tiempo porque estaba preparando la fiesta del santo patrón de la hacienda.

En cuanto a las penas de cárcel a veces decretadas por los jueces, su realidad dejaba mucho que desear. En 1701, D. Cristóbal Navarro Cóndor Quispe, indio principal de Cajamarca, mandó al protector una carta enfurecida. El vecino Santiago Martínez de Goicochea, que fuera condenado a una pena de prisión por haberle maltratado, se pasaba en realidad los días de condena en la secretaría de la cárcel, se iba a casa para comer $y$, por supuesto, dormía cada noche en el lecho conyugal...

A pesar de tales limitaciones, quizás sea posible medir la realidad de la acción del protector por las recriminaciones que su proceder podía suscitar entre los españoles contra quienes alentaba pleitos y causas. Sin ser aquellas muy numerosas, hay algunas bastante reveladoras que le acusan de favoritismo proindígena, de abusos de poder, incluso de rebelión en la medida en que a los personajes enjuiciados parece que no se les alcanzaba que sus criados indios, validos de la "complicidad" del protector -funcionario colonial, al fin $y$ al cabo- pudiesen llevarlos hasta un tribunal. Entonces, a modo de reacción, no escaseaban calumnia y mentiras. Así fue como Fernando Soriano que, como lo prueban sobrados ejemplos, fue un excelente protector a comienzos del siglo XIX, tuvo que aguantar denuncias que le acusaban de recibir cohechos de los indios 


\section{Bernard Lavalle}

$y$, por lo tanto, de suscitar de manera interesada las demandas de éstos.

El corpus que acabamos de presentar ilustra de manera original todo un sector de la vida provinciana de Cajamarca dentro y alrededor de las haciendas. Lo que nos revelan esas demandas y pleitos está conforme con lo que sabemos por otras fuentes y otros análisis de diversas regiones peruanas en la misma época. Los expedientes estudiados por el protector también muestran la capacidad de los indígenas para utilizar las posibilidades de toma de palabra y de recurso al derecho que el sistema colonial español había organizado, a manera de válvulas de escape, para los oprimidos. Su eficacia, según las regiones y los periodos, fue sin lugar a duda función de sus límites estructurales $e$ institucionales, del peso y de la presión que ejercían sobre ellos los grupos de poder, pero también de la honradez de los funcionarios encargados de poner en obra $y$, sobre todo, de la voluntad $y$ de la toma de conciencia de que podian hacerlas eficaces aquellos mismos que, desde el fondo de su miseria, iban a ser los beneficiarios. Este último punto es sin duda el más significativo de este estudio. Esa conciencia indígena no apareció en el siglo XVII; la habilidad de muchos sectores indios desde fecha temprana en jugar con las posibilidades del sistema español ya es bien conocida. Sin embargo, las quejas y demandas múltiples -en número cada vez creciente- que emanan de humildes trabajadores de las lejanas comarcas cajamarquinas son la prueba manifiesta de que, a pesar de las insuficiencias obvias -y que los indigenas por supuesto bien sabían por experiencia-, a pesar también de las dificultades que presentaba para ellos el aparato judicial colonial, los campesinos indios estaban ya determinados a reaccionar ante los abusos. 


\section{Presion colonial en Cajamarca}

Por supuesto, tanto los testimonios como los trámites se deben leer como manifestaciones "mestizas" en la medida en que los primeros fueron redactados por el protector que servía de abogado ante los tribunales y los segundos son también fruto de la obstinación de dicho protector, pero la insistencia de los indígenas en denunciar abusos, en reivindicar su libertad y el fin de su esclavitud -la palabra vuelve a menudo para designar la situación del campesino- que se les imponía, su exigencia de ser tratados como si fuesen españoles sin diferencia de ningún tipo, ${ }^{28}$ todo esto es significativo, por la fuerza con que se emite y su carácter iterativo, de los tiempos nuevos por los que atravesaba la colonia.

Tales declaraciones que a menudo van más allá del marco estrictamente personal y se hacen en nombre de "la nación india" demuestran una conceptualización de los problemas y un grado de teorización en los análisis que, en realidad, hacen de ellos unos reveladores quizás más profundos que los movimientos de rebelión que, por esas fechas, afectaron la región.

${ }^{28}$ Ver, por ejemplo, lo que escribían los indios del pueblo de San Juan de Yanac en 1812:

"En este estado nos hallamos los miserables indios siendo tan libres como los españoles a virtud que en una de las recopilaciones de Indias Su Majestad lo declara pero siendo inutiles... no estando en observancia ninguna de las leyes la corruptela se exagera del domestico y feliz estado de los miserables indios... la nación a quien ha engrandecido su real corona". 